\title{
Elective Splenectomy for Haematological Disorders: One Centre Experience
}

\author{
Jawad Ahmad, ${ }^{\mathrm{a}, \mathrm{b}}$, Sadaf Gull ${ }^{\mathrm{a}}$, Steven McCain ${ }^{\mathrm{a}}$, Roy A J Spence
}

\begin{abstract}
The spleen plays an important role in immune-surveillance and haematopoiesis. Its role in the fight against infection, especially infection of encapsulated organisms, is particularly significant. It also removes intracellular inclusions (pitting) and filters aged blood cellular elements from circulation. Although the spleen has important immune functions, elective splenectomy is sometimes indicated for excessive cellular destruction (hypersplenism) or sequestration, lymphomatous or myeloid disease or tumours. We present a sixteen year experience of elective splenectomy from a tertiary care surgery and haematology centre in Northern Ireland with a literature review.
\end{abstract}

Keywords: Splenectomy; Haematology; Elective

\section{Introduction}

The spleen plays an important role in immune-surveillance and haematopoiesis. Its role in the fight against infection, es-

Manuscript accepted for publication April 19, 2012

${ }^{a}$ Department of Surgery, Belfast City Hospital, Belfast Health and Social Care Trust, Northern Ireland

${ }^{\mathrm{b}}$ Corresponding author: Jawad Ahmad.

Email: jawad.ahmad@hotmail.co.uk

doi: $10.4021 / \mathrm{jcs} 42 \mathrm{w}$ pecially infection of encapsulated organisms, is particularly significant. It also removes intracellular inclusions (pitting) and filters aged blood cellular elements from circulation [1].

Although the spleen has important immune functions, elective splenectomy is sometimes indicated for excessive cellular destruction (hypersplenism) or sequestration, lymphomatous or myeloid disease or tumours [2].

We present a sixteen year experience of elective splenectomy from a tertiary care surgery and haematology centre in Northern Ireland with a literature review.

\section{Patients and Methods}

Population-based information was collected from the Hospital Inpatient System (HIS) in Northern Ireland (NI). This Government department has maintained up to date records of any surgical activity in the Province since records commenced in 1995. Data were searched for the key terms splenectomy and removal of spleen in an elective setting. All patients who had undergone elective splenectomy for haematological disorders at Belfast City Hospital between 1995 and 2010 were included in the study. Patients who lost their spleen for iatrogenic injury or trauma were excluded. The case notes were retrieved from the hospital records and reviewed for data collection.

Northern Ireland has maintained a relatively stable population of 1.7 million over the last two decades, 112 patients with splenectomy were identified through the HIS database, 65 of them had splenectomy for iatrogenic injury during another surgical procedure or trauma, hence they were excluded, 47 patients were included for further analysis. Seven patients had died and their case notes were destroyed and not available for review. Two patients had wrong coding and were excluded. 6 case notes were lost and could not be included in the study. Case notes of 32 patients were available for final analysis (Fig. 1).

There were 15 males and 17 females in this series. The age range was 15 to 84 years, with median age of 64 years. A breakdown of the indication of surgery, age and sex distribution, mean hospital stay and incidence of complications is presented in Table 1. 


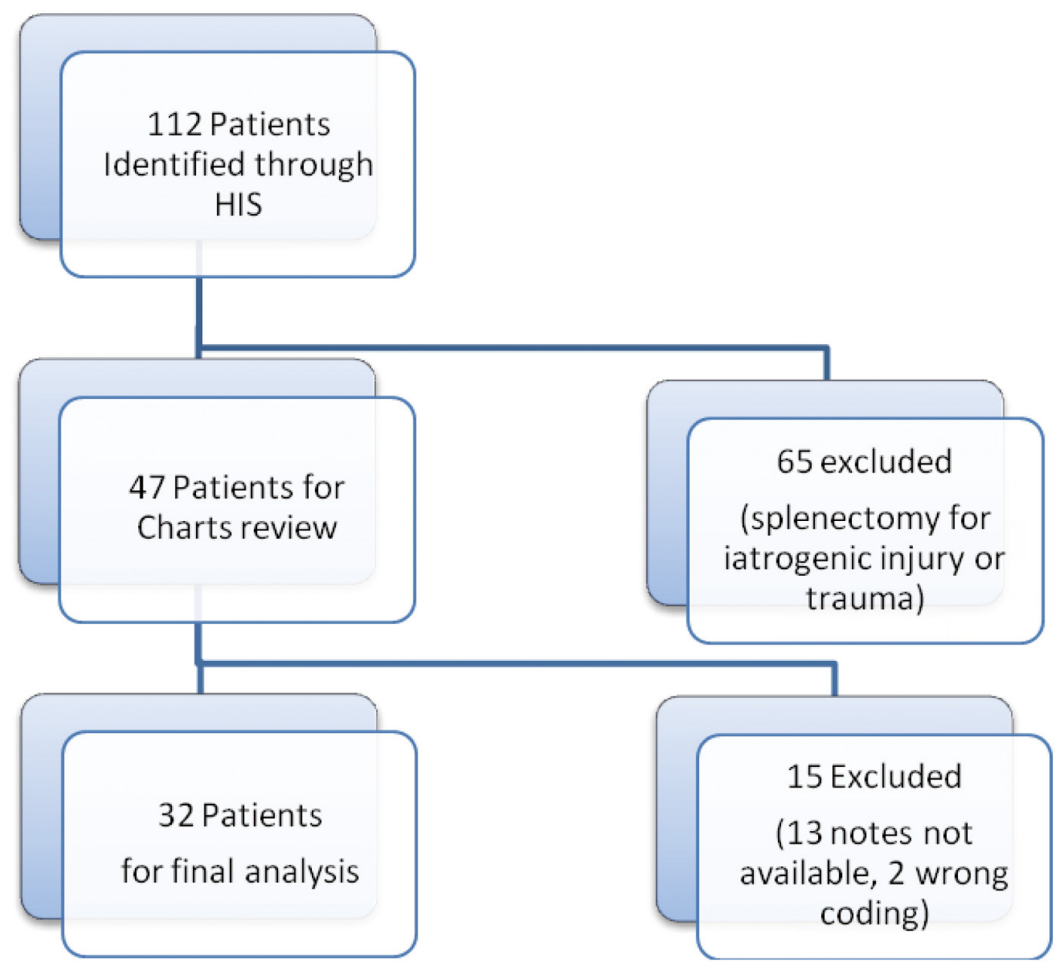

Figure 1. Flow chart showing included and excluded patients

\section{Results}

The surgical follow up was $100 \%$ complete. All patients were followed up at 6 and 12 months after surgery at a specialist surgical clinic to evaluate the outcome of splenectomy. Longer term follow up was maintained by the haematology team and is not included in this paper.

Immune Thrombocytopenic Purpura (ITP) was the indication for splenectomy in 13 patients. All patients had failed medical management or were refractory to conservative treatment and were on high dose steroids at the time of surgery. The response to splenectomy was assessed clinically and haematologically at 6 and 12 months. In all cases, the response to surgery was good with a significant improvement in platelet count.

Seven patients had a diagnosis of lymphoma and four were diagnosed with Myeloid Disease (MD), including one with Hairy Cell Leukaemia. There were four patients with Hereditary Spherocytosis (HS) and three with Autoimmune Haemolytic Anaemia (AHH). All of these patients had a good response to splenectomy at long term follow up, measured by their steroids and transfusions requirements. A female patient was diagnosed with Evan's syndrome (autoimmune haemolytic anaemia with autoimmune thrombocytopenia). Splenectomy was curative in this case at 10 years follow-up.

A breakdown of the year of splenectomy with specific indications is presented in Figure 2. The graph shows trends of splenectomy in NI however, the numbers are too small to point towards a change in splenectomy practice due to improved and modern management of haematological disorders. There was no 30 day or in-hospital death in this series.

All patients received pre-operative polyvalent pneumococcus, Haemophilus influenza B and Meningococcus vaccinations. Post-operatively, all patients were on lifelong antibiotic prophylaxis with oral antibiotics (penicillin or erythromycin).

\section{Discussion}

Common indications for elective splenectomy for haematological disorders are Immune Thrombocytopenic Purpura (ITP), lymphoma, Myeloid Disease (MD), Hereditary Spherocytosis (HS) and Autoimmune Haemolytic Anaemia (AHH). Elliptocytosis, sickle cell anaemia and thallassaemia are among the uncommon indications [2]. Our practice in NI reflects the pattern that ITP is the most common indication for splenectomy, followed by lymphoma, MD and haemolytic anaemia. Although laparoscopic splenectomy is the favoured approach where expertise exists, open surgery is equally safe with reasonable safety, efficacy and patient acceptance [3]. In future, small spleens of ITP will usually be removed laparoscopically.

There was no mortality in our case series and only mini- 
Table 1. Diagnosis and Complications of Elective Splenectomy Between 1995 and 2010

\begin{tabular}{|c|c|c|c|c|c|}
\hline Diagnosis & $\begin{array}{l}\text { n } \\
(32)\end{array}$ & $\begin{array}{l}\text { Mean Age } \\
\text { at Diagnosis } \\
\text { (years) }\end{array}$ & $\begin{array}{l}\text { Male to } \\
\text { Female Ratio }\end{array}$ & $\begin{array}{l}\text { Mean Hospital } \\
\text { Stay (days) }\end{array}$ & Complications \\
\hline $\begin{array}{l}\text { Immune Thrombocytopenic } \\
\text { Purpura (ITP) }\end{array}$ & 13 & 47 & $1: 2$ & 6.5 & $\begin{array}{l}3 \text { chest infections } \\
3 \text { incisional hernia } 1 \\
\text { pancreatic fistula } \\
1 \text { DVT }\end{array}$ \\
\hline Lymphoma & 7 & 60 & $3: 4$ & 10 & $\begin{array}{l}1 \text { wound infection } \\
1 \text { incisional hernia }\end{array}$ \\
\hline Myeloid Disease (MD) & 4 & 62 & $1: 1$ & 7 & None \\
\hline Hereditary Spherocytosis (HS) & 4 & 16 & $3: 1$ & 5 & None \\
\hline $\begin{array}{l}\text { Autoimmune Haemolytic } \\
\text { Anemia (AHH) }\end{array}$ & 3 & 56 & $2: 1$ & 7 & 1 wound infection \\
\hline Evan's Syndrome (ES) & 1 & 34 & Female & 20 & Chest infection \\
\hline
\end{tabular}

mal morbidity. Some of the morbidity may be precipitated by the fact that many of these patients were immuno-compromised through the use of high dose steroids, immunosuppressants and multiple blood transfusions [4].

Presence of splenunculi can result in late recurrence of ITP and may need excision [5]. In this series however, there was no incidence of the presence of a splenunculus per-operatively or evidence on long-term (2 - 3 years) follow-up.
Presence of intra-erythrocytic inclusions in the peripheral blood film (Howell Jolly Bodies) would suggest asplenia [6]. This is a useful marker when assessing success in patients who have undergone splenectomy for haematological conditions. Absence of previously present Howell Jolly bodies is pathognomic of presence of a splenunculus and 99Tcmlabelled red blood scan or MRI is useful to make a diagnosis $[7,8]$. We did not come across a situation where splenunculi

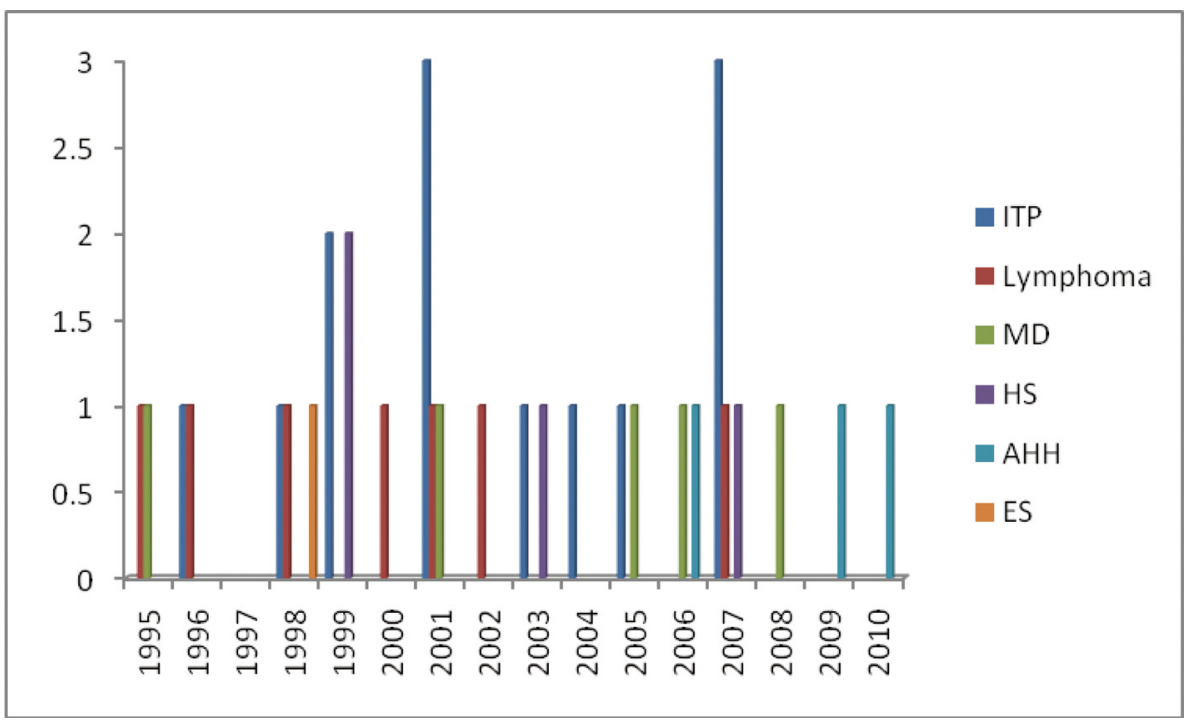

Figure 2. Trends of elective splenectomy between 1995 and 2010 
were a concern in patients treated with splenectomy in this series.

The ITP group of patients had the highest incidence of complications in our cohort of patients. The only major complication of pancreatic fistula (which was successfully managed conservatively) also occurred in this category. These patients were immunosuppressed pre-operatively as all were on high dose steroids when presented for surgery.

Splenectomy is rarely required for staging or diagnosis of lymphoma or MD [9]. This was the case in this series as splenectomy was only carried out for symptomatic massive spleens and for hypersplenism in patients with lymphoma and MD.

All patients with HS in our series had severe disease and were transfusion dependent. There was no incidence of gallstones at the time of surgery; hence concomitant cholecystectomy was not performed. Median age at splenectomy for patients with HS was 16 years which reflects the disease pattern [10]. Although partial splenectomy is an alternative approach for these patients and it has been claimed to provide sustained and clinically significant improvement in haematological profiles [11], our institutional practice has been a total splenectomy. Our long-term results have confirmed a sustained haematological improvement in these patients. While this series represents open splenectomy for patients, most of whom had significantly enlarged spleen (some with massive enlargement), we recognise that laparoscopic splenectomy for small ITP spleen carries advantages.

IgG AHA patients who fail medical management or are on high dose steroids benefit from splenectomy. Our cases in this series comprised patients with IgG AHA and benefited from splenectomy [12]. Splenectomy does not have a role in IgM AHA.

Evan's syndrome is a rare condition where patients develop AHA in addition to autoimmune thrombocytopenia. Splenectomy is curative in $40 \%$ of cases [13]. This was the case in the patient who underwent splenectomy in our unit.

In conclusion, our practice conforms to the national and international standards with regards to the indications and safety of open splenectomy. Patients with complex haematology disorders are best served in a tertiary care surgery and haematology centre to maintain good safety and efficacy profile within a multidisciplinary team setting, not only preoperatively but also in the post-operative period.

\section{Abbreviations}

Hospital Inpatient System (HIS), Northern Ireland (NI), Immune Thrombocytopenic Purpura (ITP), Myeloid Disease (MD), Hereditary Spherocytosis (HS), Autoimmune Heamolytic Anaemia (AHH), Evan's Syndrome (ES).

\section{Declaration}

All the authors declare that none of them or their institution at any time received payment or services from a third party for any aspect of this work or have any other relationships/ conditions/circumstances that could present a potential conflict of interest.

\section{References}

1. Cesta MF. Normal structure, function, and histology of the spleen. Toxicol Pathol. 2006;34(5):455-465.

2. Katz SC, Pachter HL. Indications for splenectomy. Am Surg. 2006;72(7):565-580.

3. Bani Hani MN, Qasaimeh GR, Bani-Hani KE, Alwaqfi NR, Al Manasra AR, Matani YS, El-Radaideh KM. Laparoscopic splenectomy: consensus and debatable points. S Afr J Surg. 2010;48(3):81-84.

4. Kim SH, Lee SI, Noh SM. Prognostic significance of preoperative blood transfusion in stomach cancer. J Gastric Cancer. 2010;10(4):196-205.

5. Hann IM, Wainscoat JS. Recurrent thrombocytopenic purpura associated with accessory spleen. Arch Dis Child. 1976;51(2):154-156.

6. Sears DA, Udden MM. Howell-Jolly Bodies: A Brief Historical Review. Am J Med Sci. 2011.

7. Spencer GR, Bird C, Prothero DL, Brown TR, Mackenzie FA, Phillips MJ. Spleen scanning with 99Tcmlabelled red blood cells after splenectomy. Br J Surg. 1981;68(6):412-414.

8. Muzammil S, Kanyike FB. MRI: a valuable tool in diagnosis of splenunculus in chronic idiopathic thrombocytopenic purpura. N Z Med J. 2008;121(1268):U2902.

9. Rueffer U, Sieber M, Stemberg M, Gossmann A, Josting A, Koch T, Grotenhermen F, et al. Spleen involvement in Hodgkin's lymphoma: assessment and risk profile. Ann Hematol. 2003;82(7):390-396.

10. Barcellini W, Bianchi P, Fermo E, Imperiali FG, Marcello AP, Vercellati C, Zaninoni A, et al. Hereditary red cell membrane defects: diagnostic and clinical aspects. Blood Transfus. 2011;9(3):274-277.

11. Buesing KL, Tracy ET, Kiernan C, Pastor AC, Cassidy LD, Scott JP, Ware RE, et al. Partial splenectomy for hereditary spherocytosis: a multi-institutional review. J Pediatr Surg. 2011;46(1):178-183.

12. Michel M. Classification and therapeutic approaches in autoimmune hemolytic anemia: an update. Expert Rev Hematol. 2011;4(6):607-618.

13. Duperier T, Felsher J, Brody F. Laparoscopic splenectomy for Evans syndrome. Surg Laparosc Endosc Percutan Tech. 2003;13(1):45-47. 